\title{
Informing the development of an Internet-based chronic pain self-management program
}

\author{
Amédé Gogovor $^{\mathrm{a}}$, Regina Visca ${ }^{\mathrm{b}}$, Claudine Auger $^{\mathrm{c}, \mathrm{d}}{ }^{\text {, Lucie Bouvrette-Leblanc }}{ }^{\mathrm{e}, \mathrm{h}}$, \\ Iphigenia Symeonidis $^{\mathrm{a}}$, Lise Poissant ${ }^{\mathrm{c}, \mathrm{d}}$, Mark A. Ware ${ }^{\mathrm{f}}$, Yoram Shir ${ }^{\mathrm{f}}$, Natacha Viens ${ }^{\mathrm{e}}$, \\ Sara Ahmed ${ }^{\mathrm{a}, \mathrm{d}, \mathrm{g}, *}$
}

a Division of Clinical Epidemiology, McGill University Health Centre, Montreal, Canada

${ }^{\mathrm{b}}$ RUIS McGill Centre of Expertise in Chronic Pain, Montreal, Canada

' School of Rehabilitation, Université de Montréal, Montreal, Canada

${ }^{\mathrm{d}}$ Centre for Interdisciplinary Research in Rehabilitation of Greater Montreal, Montreal, Canada

e Constance-Lethbridge Rehabilitation Centre, Montreal, Canada

${ }^{\mathrm{f}}$ Alan Edwards Pain Management Unit, McGill University Health Centre, Montreal, Canada

${ }^{g}$ School of Physical \& Occupational Therapy, McGill University, Montreal, Canada

h Sherbrooke University, Sherbrooke, Canada

\section{A R T I C L E I N F O}

\section{Article history:}

Received 20 August 2015

Received in revised form 5 August 2016

Accepted 3 October 2016

\section{Keywords:}

Chronic pain

Self-management

Internet-based program

e-health

\begin{abstract}
A B S T R A C T
Background: Self-management can optimize health outcomes for individuals with chronic pain (CP), an increasing fiscal and social burden in Canada. However, self-management is rarely integrated into the regular care (team activities and medical treatment) patients receive. Health information technology offers an opportunity to provide regular monitoring and exchange of information between patient and care team.

Objective: To identify information needs and gaps in chronic pain management as well as technology features to inform the development of an Internet-based self-management program.

Methods: Two methods were used. First was a structured literature review: electronic databases were searched up to 2015 with combinations of MeSH terms and text-words such as chronic pain, selfmanagement, self-efficacy, technology, Internet-based, patient portal, and e-health. A narrative synthesis of the characteristics and content of Internet-based pain management programs emerging from the literature review and how they relate to gaps in chronic pain management were completed. Second, four audiotaped focus group sessions were conducted with individuals with chronic pain and caregivers $(n=9)$ and health professionals $(n=7)$ recruited from three multidisciplinary tertiary and rehabilitation centres. A thematic analysis of the focus group transcripts was conducted.

Results: Thirty-nine primary articles related to 20 patient-oriented Internet-based programs were selected. Gaps in CP management included lack of knowledge, limited access to health care, suboptimal care, and lack of self-management support. Overall, 14 themes related to information needs and gaps in care were identified by both health professionals and patients, three were exclusive to patients and five to health professionals. Common themes from the focus groups included patient education on chronic pain care, attitude-belief-culture, financial and legal issues, end-of-program crash, and motivational content. Conclusions: Internet-based programs contain automated, communication and decision support features that can address information and care gaps reported by patients and clinicians. However, focus groups identified functionalities not reported in the literature, non-medical and condition- and context-specific information, integration of personal health records, and the role of the different health professionals in chronic pain management were not identified. These gaps need to be considered in the future development of Internet-based programs. While the association between the mechanisms of Internetbased programs' features and outcomes is not clearly established, the results of this study indicate that interactivity, personalization and tailored messages, combined with therapist contact will maximize the effectiveness of an Internet-based chronic pain program in enhancing self-management.
\end{abstract}

(C) 2016 Elsevier Ireland Ltd. All rights reserved.

\footnotetext{
* Corresponding author at: RI-MUHC Div. of Clinical Epidemiology, ROSS Building, 687 Pine Ave W, Room 4.15, Montreal, QC H3A 1A1, Canada.

E-mail address: sara.ahmed@mcgill.ca (S. Ahmed).
} 


\section{Introduction}

Despite its wide prevalence, chronic pain remains one of the most under-recognized and under-treated medical problems in the Western world [1-3]. Back pain, headaches, and arthritis/joint pain are the most common pain problems [4,5]. Chronic pain may lead to disability, poor quality of life, early retirement, and increased health care utilization costs [6]. In Canada, the prevalence of chronic pain ranges from $15 \%$ to $18 \%$ of the general population, and the costs for treatment and lost productivity due to chronic pain are estimated to be \$10-15 billion annually [7]. Thus, early and optimal management is necessary to alleviate the increasingly crippling effects of chronic pain on the healthcare system and society.

Many challenges exist in the management of chronic pain [8]. First, best practices for pain management often require coordinated interdisciplinary assessment and management [9]. This type of care is available in only a limited number of existing multidisciplinary clinics, leaving patients with fragmented services that lack an interdisciplinary approach. When they do exist, multidisciplinary clinics have long waiting lists and are poorly integrated into primary health care and community-based services [10]. In addition to medical treatment, individuals with chronic pain require psychological services and care by allied health professionals, which are often limited or not available [11]. These challenges are further compounded by the tendency for patients and physicians to perceive chronic pain as a symptom of an underlying health condition, a tendency to manage pain with an acute rather than a chronic model of care, and reluctance to prescribe medications [11-13].

Individuals with chronic pain require considerable professional self-management support and long-term follow-up by the care team to enable their full engagement in their care and life. Selfmanagement (SM) support is defined as "the systematic provision of education and supportive interventions by health care staff to increase patients' skills and confidence in managing their health problems, including regular assessment of progress and problems, goal setting, and problem-solving support." [14].

Because of limited healthcare resources and trained case managers who can deliver SM support, and restricted mechanisms for ongoing follow-up and communication with the care team, SM is rarely integrated into regular care team activities or the medical treatment patients receive $[15,16]$. In this context, information technologies such as Internet-based programs are expected to provide solutions for three areas that are relevant to chronic disease self-management by: (1) ongoing monitoring of patient knowledge and symptoms, and feedback from the care team to help patients adopt healthy behaviours and avoid risky behaviours; (2) increasing patient knowledge outside of the clinical encounter, providing enhanced education; and (3) sharing of clinical information and treatment goals with patients by giving them access to their personal health records $[17,18]$. In addition, studies have shown that adolescents as well as older adults will use and benefit from online interventions [19-22].

Although dramatic advances in Internet-based technology hold the promise of major advances in e-health solutions for the management of chronic pain and other chronic diseases [23-36], there are considerable challenges when implementing technology in health care [37-39], and a relative paucity of scientific knowledge to guide the development, implementation, and outcome evaluation of effective choices [40]. Review papers on Internet-based interventions for chronic pain are scarce and mainly focus on their effectiveness, with some description of their content and the features of the Internet-based programs [19,22,41,42]. A recent review showed promising effects of Internet-delivered therapies for different chronic pain conditions, but the authors did not identify the required information on the relationship between content, technology features and treatment outcomes [43]. Thus new studies are necessary to palliate the lack of data. The development of an Internet-based program and the quality and appropriateness of its content constitute a crucial step in its successful implementation and adoption by end users [44,45]. Links must be made between Internet-based programs and the self-management needs of individuals, clinical workflow, and existing services. What features will patients and clinicians value? What features will increase engagement, self-efficacy, and adherence to the program and positively impact treatment outcomes?

The aim of this study was to identify information needs and gaps in chronic pain management and technology features to inform the development of an Internet-based self-management program that could address the issues, and ultimately help improve chronic pain management outcomes. Specific objectives were: (i) to identify and define the features of existing Internet-based programs for chronic pain and the gaps in chronic pain management they address; (ii) to evaluate clinician and patient perceptions of both chronic pain management and the characteristics of Internet-based programs they believe can improve chronic pain management and support patient self-management; and (iii) to summarize the features that will inform the future development and implementation of an integrated Internet-based self-management program.

\section{Methods}

Two methods were used to identify gaps in chronic pain selfmanagement and the features of an Internet-based program: (1) a structured literature review, and (2) focus groups with patients and caregivers, and health professionals working in chronic pain management and rehabilitation.

\subsection{Literature review}

Using search strategies that were developed with the help of a librarian and with combinations of MeSH terms and text-words (chronic pain, self-management, self-efficacy, attitude to health, health promotion, self care, technology, internet-based, patient portal, e-health, online intervention, internet-based intervention, telephone, cellular phone, mobile phone, electronic mail, internet, email) the following databases were searched initially up to 2011: AMED, MEDLINE (PubMed), Embase (Ovid), PsycINFO (Ovid), CINAHL (EBSCO), Cochrane Library, and ISI Web of Science. Englishlanguage articles or Internet-based programs that address gaps in chronic pain management or the use of technology to support patient self-management were selected based on the following inclusion criteria: (1) chronic pain management, (2) Internet-based systems for pain management (computer/mobile), and (3) patients as end users. In addition, reference lists from the selected and review papers were examined. Finally, alerts based on the search strategies were used to update the searches with more recent articles up to January 2015.

\subsection{Focus groups}

To identify relevant features of Internet-based programs for end-users, we held four focus group sessions [46,47] with health professionals and individuals with chronic pain and caregivers. The first two focus groups included seven health professionals working in chronic pain prevention and management. The last two focus groups included patients and caregivers because of their roles and information needs [19,48]. All focus group participants were recruited from two rehabilitation centres of the Centre for Interdisciplinary Research in Rehabilitation (CRIR), and from the pain unit of the McGill University Health Centre (MUHC). The participants were adults 18 years of age or older who had completed a 


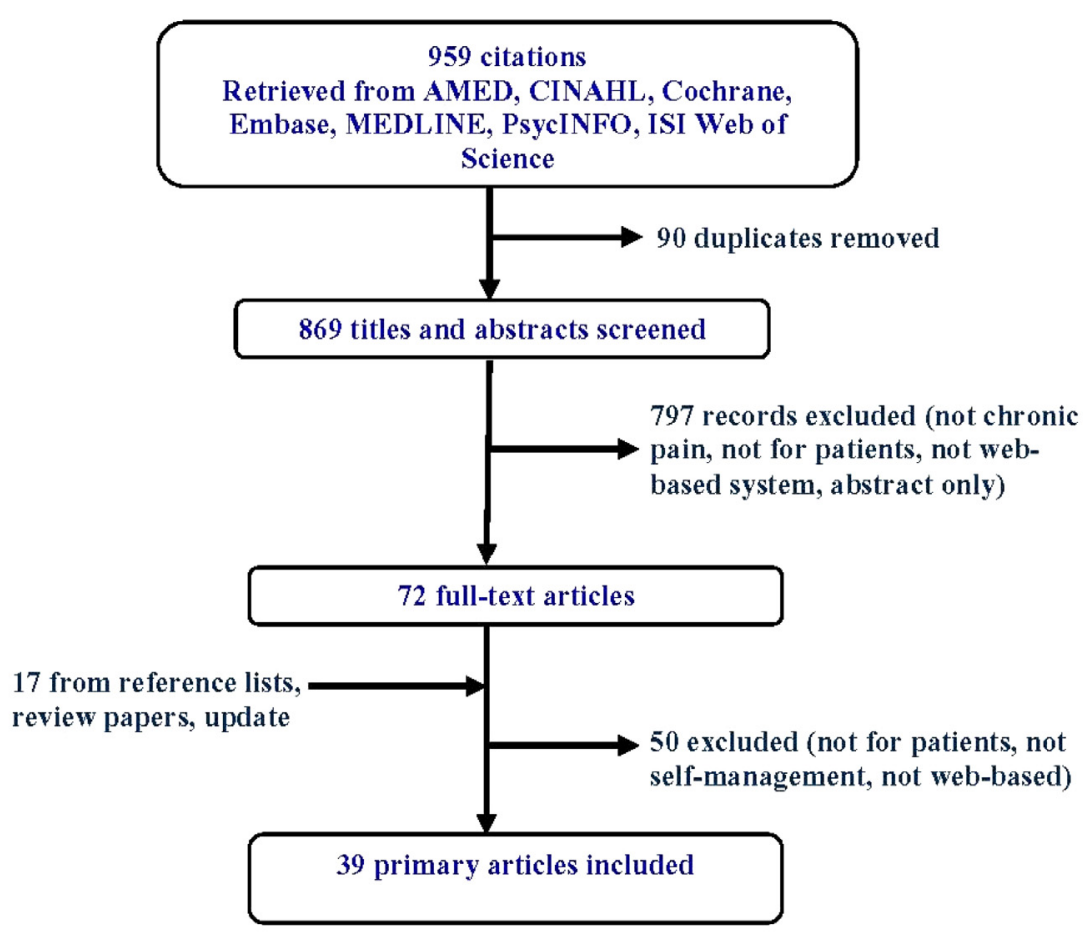

Fig. 1. Article selection flowchart.

chronic pain rehabilitation program. Two focus groups were conducted in French, one with four health professionals and the other with four individuals with chronic pain and one caregiver. The other two focus groups were conducted in English with three health professionals and five individuals with chronic pain. One individual was both patient and caregiver.

To structure discussions during the focus groups, common domains identified from the literature review and from previous work [49] were used to develop two sets of open-ended questions (Tables A1 \& A2, Supplementary material). Questions were selected to cover experience with chronic pain management, use of technologies in clinical care, patient-provider communications, and expected content in an Internet-based program. The aim was to collect information that would help elicit links between needs for chronic pain self-management support and features in an Internetbased program. Each focus group session was facilitated by a member of the research team and a moderator who took notes and assisted with clarifications. The sessions with health professionals and patients lasted two hours. Participants completed a pre-focus group questionnaire. Health professionals were asked about their specialty and clinical experience. Patients and caregivers provided information about their sociodemographic characteristics, health status, and computer literacy. All sessions were audiotaped and transcribed in full.

\subsection{Analysis}

\subsubsection{Literature review}

A narrative synthesis was completed on the content of the selected articles with respect to the objectives and gaps in chronic pain management, type of chronic pain, target population, type of platform, country, purpose and features of Internet-based programs based on the classification model of Webb et al. [50], determinants of acceptability and usability, and usage patterns of the Internet-based programs. The gaps in chronic pain management addressed by the Internet-based programs were retrieved from the selected articles; these gaps were then grouped into four categories based on their similarities and a proportion was computed (number of articles that mentioned a gap category/total number of articles). Webb's classification divides features into 3 main categories: (i) automated functions that include the use of an enriched information environment, automated tailored feedback, and automated follow-up messages, (ii) communicative functions such as access to an expert for advice, scheduled contact with an expert, such as by email, peer-to-peer access, and (iii) use of supplementary modes, including the use of email, phone, short messaging service (SMS), CD-ROM, and videoconferencing [50].

\subsubsection{Focus groups}

Using an inductive approach and thematic analysis, transcripts from the focus groups were reviewed independently by two members of the research team (AG, IS) to generate overall codes [51]. Coding discrepancies were discussed, and similar codes were organized into themes and categories according to the objectives.

\subsubsection{Synthesis}

Two team members (AG, IS) synthesized and compared features identified from the literature and the focus group themes to define the characteristics needed for an Internet-based chronic pain selfmanagement program. These characteristics were grouped based on Webb's classification.

\subsection{Ethics review board approval}

The study was approved by the research ethics boards of the CRIR and MUHC. All participants were provided with information about the study, and written consent was obtained. 


\section{Results}

\subsection{Literature review}

\subsubsection{Description of the articles}

Based on the inclusion criteria, thirty-nine primary articles (related to 20 scientific, professional and patient-oriented Internet-based programs) were selected from multiple sources: electronic searches, articles' reference lists, and review papers $[19,22,41,42,52-55]$ (see article selection flowchart, Fig. 1). The majority of the papers (59\%) described pilot or full-scale randomized controlled trials, while four studies (10\%) used a combination of quantitative and qualitative methods. Nearly half of the Internetbased programs were designed in the United States (45\%), followed by Canada, Germany, Sweden and United Kingdom (10\% each), and Netherlands, Norway and Switzerland (5\% each). The objectives of the selected articles included describing the design as well as assessing the acceptability and usability of Internet-based programs (31\%), evaluating their effectiveness (54\%), determining the feasibility of Internet-based self-management programs (13\%), evaluating the incremental utility of Internet-based programs, and examining their features most commonly used by patients (10\%). These programs were intended to address one or more of the following gaps in chronic pain management: lack of knowledge (15\%), limited access to health care (44\%), suboptimal care (28\%), and lack of self-management support (38\%).

\subsubsection{Classification and features of the Internet-based programs}

Characteristics and common features of the 20 Internet-based programs described in the selected articles are shown in Table 1. Thirty percent were designed for chronic pain and $10 \%$ for multiple chronic conditions in general, 30\% focused on headache or migraine, $20 \%$ on chronic (low back) pain and arthritis, respectively, and $15 \%$ on fibromyalgia. The target population for the majority of the Internet-based programs ( $80 \%$ ) was adults, including one for older adults ( $\geq 55$ years); the other four (20\%) were for adolescents and their parents with separate sections for each, but parents were able to view all the materials across the entire Internet-based program. Based on Webb's classification of the features [50], 18 (90\%) of the Internet-based programs had automated functions, 9 (45\%) had some type of communicative functions, and 11 (55\%) used supplementary modes of delivery (Table 1 ).

There were different patterns of usage, mainly related to the automated functions category, subcategories of using an enriched environment and automated tailored feedback based on individual monitoring (e.g. survey application with interactive questions, periodic pain tracker), and the communicative functions category in Webb's mode of delivery classification [50]. Exercise and relaxation techniques were the most commonly used skills for one Internet-based program [56], while the library (information centre) was by far the most heavily used section, followed by the exercise and forum sections, of the 'Oneself' tool [57]. While all of the Internet-based programs had some level of interactivity, 55\% were moderated by a health professional through synchronous (forum) and asynchronous (chat room) [58-60] communication. Finally, only one program included access to health records allowing users and others to view medical records and lab tests.

\subsection{Focus groups}

\subsubsection{Participants}

The characteristics of the participating health professionals, patients and caregivers are shown in Tables 2 and 3, respectively. The health professionals' experience ranged from 2 to 29 years as a physician, nurse, physiotherapist, psychologist, special care counsellor, or orthopedic specialist. Of the patient and care-
Table 1

Characteristics of Internet-based tools in the selected articles ${ }^{\mathrm{a}}$.

\begin{tabular}{|c|c|c|}
\hline Item & Description & $\mathrm{N}=20^{\mathrm{b}}$ \\
\hline \multirow[t]{2}{*}{ Platform } & Computer web-based & 16 \\
\hline & $\begin{array}{l}\text { Computer and mobile } \\
\text { web-based }\end{array}$ & 4 \\
\hline \multirow[t]{2}{*}{ Moderation } & $\begin{array}{l}\text { Monitored by health } \\
\text { professional }\end{array}$ & 11 \\
\hline & Automatic (not monitored) & 9 \\
\hline \multirow[t]{7}{*}{ Conditions } & Chronic pain & 6 \\
\hline & Headache/migraine & 6 \\
\hline & Arthritis/osteoarthritis & 4 \\
\hline & Chronic (low) back pain & 4 \\
\hline & Fibromyalgia & 3 \\
\hline & $\begin{array}{l}\text { Chronic conditions (including } \\
\text { pain) }\end{array}$ & 2 \\
\hline & Cancer pain & 1 \\
\hline \multirow[t]{3}{*}{ Target population } & Adolescents and parents & 4 \\
\hline & Adults $(\geq 18 \mathrm{y})$ & 15 \\
\hline & Older adults ( $\geq 55 \mathrm{y})$ & 1 \\
\hline \multirow[t]{12}{*}{ Features } & $\begin{array}{l}\text { Automated functions } \\
\text { [56,58,61,64,65,68,72,73,91-100] } \\
\text { - Enriched information } \\
\text { environment (e.g. } \\
\text { supplementary content and } \\
\text { links, testimonials, videos, } \\
\text { and games) }\end{array}$ & 11 \\
\hline & $\begin{array}{l}\text { - Automated tailored feedback } \\
\text { based on individual progress } \\
\text { monitoring (e.g., daily } \\
\text { tracker, comparison to } \\
\text { norms or goals, reinforcing } \\
\text { or coping messages, } \\
\text { feedback on instructions and } \\
\text { assignments, goal } \\
\text { attainment, patient's } \\
\text { condition) }\end{array}$ & 10 \\
\hline & $\begin{array}{l}\text { - Automated follow-up } \\
\text { messages (e.g., reminders, } \\
\text { tips, motivational feedback) }\end{array}$ & 5 \\
\hline & $\begin{array}{l}\text { Communicative functions } \\
{[58,60,65,73,96,97,100-102]}\end{array}$ & \\
\hline & $\begin{array}{l}\text { - Access to advisor for advice } \\
\text { (e.g., "ask the expert" facility, } \\
\text { expert-led discussion board } \\
\text { or chat sessions) }\end{array}$ & 5 \\
\hline & $\begin{array}{l}\text { - Scheduled contact with } \\
\text { advisor (e.g., emails) }\end{array}$ & 3 \\
\hline & $\begin{array}{l}\text { Peer-to-peer access (e.g., } \\
\text { buddy systems, peer-to-peer } \\
\text { discussion boards, forums or } \\
\text { live chat, pain management } \\
\text { tips from peers) }\end{array}$ & 4 \\
\hline & $\begin{array}{l}\text { Use of supplementary modes } \\
{[58-60,62,68,73,74,94,96,97,99-103]}\end{array}$ & \\
\hline & - Email & 10 \\
\hline & - Telephone & 3 \\
\hline & $\begin{array}{l}\text { - SMS (Short Messaging } \\
\text { Service) }\end{array}$ & 2 \\
\hline & - CD-ROM & 2 \\
\hline
\end{tabular}

\footnotetext{
Adapted from $[50,55]$

b N represents the number of Internet-based tools $(\mathrm{N}=20)$ but the numbers shown do not add up to 20 since they relate to more than one type of condition and feature.
} 
Table 2

Characteristics of health professional participants.

\begin{tabular}{|c|c|c|c|c|}
\hline Participant & Field of expertise & Years of experience & Care setting & Purpose/overall objective \\
\hline 1 & Neuropsychology and psychology & 9 & $\begin{array}{l}\text { Hospital-based pain } \\
\text { management centre }\end{array}$ & $\begin{array}{l}\text { Intensive functional } \\
\text { rehabilitation }\end{array}$ \\
\hline 2 & Physiotherapy & 29 & Rehabilitation hospital & $\begin{array}{l}\text { Intensive functional } \\
\text { rehabilitation }\end{array}$ \\
\hline 3 & Special care counsellor & 2 & Rehabilitation centre & $\begin{array}{l}\text { Social integration } \\
\text { rehabilitation }\end{array}$ \\
\hline 4 & Orthopedic specialist & 9 & Rehabilitation centre & Social reintegration \\
\hline 5 & Nurse pain clinician & 10 & $\begin{array}{l}\text { Tertiary pain management } \\
\text { unit }\end{array}$ & $\begin{array}{l}\text { Reduce pain and improve } \\
\text { quality of life; provide teaching } \\
\text { and conduct research }\end{array}$ \\
\hline 6 & Family medicine & 12 & $\begin{array}{l}\text { Tertiary multidisciplinary } \\
\text { pain clinic }\end{array}$ & $\begin{array}{l}\text { Evaluate and treat complex } \\
\text { pain syndromes }\end{array}$ \\
\hline 7 & Physiotherapy & 14 & Rehabilitation hospital & $\begin{array}{l}\text { Provide functional } \\
\text { rehabilitation to help patients } \\
\text { return home }\end{array}$ \\
\hline
\end{tabular}

Table 3

Characteristics of patient and caregiver participants.

\begin{tabular}{|c|c|c|c|c|c|c|c|}
\hline $\mathrm{P}$ & Age & Sex & $\begin{array}{l}\text { Self-reported } \\
\text { health status }^{\mathrm{a}}\end{array}$ & Employment status & High school completed & $\begin{array}{l}\text { Health status today } \\
\text { compared to the past }\end{array}$ & $\begin{array}{l}\text { Obtain advice about } \\
\text { my health on internet }\end{array}$ \\
\hline 1 & 42 & M & $50 / 100$ & On disability or sick leave & No & $\begin{array}{l}\text { About the same as } \\
\text { usual }\end{array}$ & Disagree \\
\hline 2 & 69 & $\mathrm{~F}$ & $80 / 100$ & Housework or family care & Yes & Worse than usual & Strongly disagree \\
\hline 3 & 46 & M & $70 / 100$ & Full or part-time paid work & No & $\begin{array}{l}\text { About the same as } \\
\text { usual }\end{array}$ & Strongly agree \\
\hline 4 & 43 & $\mathrm{~F}$ & $50 / 100$ & On disability or sick leave & Yes & $\begin{array}{l}\text { About the same as } \\
\text { usual }\end{array}$ & Strongly agree \\
\hline 5 & 47 & $\mathrm{~F}$ & $45 / 100$ & On disability or sick leave & Yes & Worse than usual & Strongly disagree \\
\hline 6 & 48 & $\mathrm{~F}$ & $45 / 100$ & Unemployed & Yes & Worse than usual & Agree \\
\hline 7 & 64 & $\mathrm{~F}$ & $50 / 100$ & Retired & No & Worse than usual & Agree \\
\hline 8 & 32 & $\mathrm{~F}$ & $65 / 100$ & On disability or sick leave & Yes & Worse than usual & Agree \\
\hline 9 & 67 & $\mathrm{~F}$ & $40 / 100$ & Retired & Yes & Worse than usual & Disagree \\
\hline
\end{tabular}

a Current health status from 0 (worst state) to 100 (best state).

b Compared to your health in the past, is your health today: better than usual, about the same as usual, worse than usual?

c Please rate the following statement concerning your computer usage: I use a computer to obtain advice about my health: strongly disagree, disagree, neutral, agree, strongly agree.

giver participants, $78 \%$ were female and $67 \%$ had completed high school. All but one participant had a score below 80 out of 100 for self-reported health, and only one participant was employed. The majority of the patients (55.6\%) agreed or strongly agreed that they used the Internet to obtain advice about their health.

\subsubsection{Health professionals}

Themes that emerged from the health professionals' accounts were related to their experience working with chronic pain clients, factors influencing pain management, and content of Internetbased program. The themes were related to the needs that the health professionals perceived patients as having as well as their own professional needs to deliver optimal patient care.

Educating patients on what chronic pain care actually involves emerged as a key theme. All the health professional participants said they provided some kind of education to their patients at the beginning of the treatment process. This provision of education included: presenting treatment program activities to patients in video orientation sessions, setting goals, teaching specific coping skills, dealing with emotions, explaining the multidisciplinary/interdisciplinary approach because it is important for patients to understand each care team member's role. "It is primarily about education. So they understand the importance of interdisciplinarity and the approach of using several management strategies through various small tools. In a nutshell, everything involving education is step one."

The second important theme was patient attitude, belief and culture. According to the health professionals, the following patient characteristics had some influence on how patients managed their health and interacted with their health care providers. Patients' attitude, belief and culture contributed to challenges to effective communication and the treatment process. This sometimes resulted in denial of the health condition, the belief that pain is only physical, medication being refused. "He says: I tried everything. When someone tells me I tried everything, I say no, you haven't tried everything". Cultural, gender and living environment (rural versus urban) differences were also mentioned: "They [some patients] will try to manage without medication and be stoic."

Financial and legal issues were mentioned as other factors of influence. The effects included missing scheduled visits and difficulty accessing the Internet because of a lack or scarcity of financial resources. According to some health professionals, pharmacological treatment by the team is kept to a minimum if the patient is engaged in disability benefit procedures or litigation with payors.

Most health professional participants also mentioned the endof-program crash encountered by individuals with chronic pain when their pain management sessions end because they have to leave trusted health professionals, may encounter a lack of flexibility in going back to work (difficulty securing a part-time flexible position), and some consequences including reverting to old behaviours. The health professionals also mentioned patients' fear of acknowledging improvements in treatment because they would need to explain their 'unreadiness' to return to work despite the improvements in order to keep their disability benefits or get them extended.

Deficiencies in care management for individuals with chronic pain include the problem of long waiting lists and delays, lack of needed referrals to other health professionals, lack of care tailored 
to specific conditions, lack of appropriate community services, poor coordination of care and poor integration of all health professional services. This is illustrated by the following quotes: "We don't want a piecemeal approach", "It's not what disease the patient has, but which patient has the disease", "Lack of integration of all the health care professionals dealing with the patient simultaneously".

For health professionals, health information technology and Internet-based programs in particular can be considered a technology for education for individuals with chronic pain. Around this theme, they mentioned different ways an Internet-based system can be used to improve certain aspects of care. The platform they suggested included not just computer-based systems, but also mobile devices with relevant applications, interactive TV, and flat screens that can be used in waiting rooms by patients or in clinical exam room by healthcare providers. "And if there are sites, platforms must be mobile so that they [websites] are accessible on mobile phones because ... everyone under 40 has a smart phone or almost." In terms of the role of Internet-based tools in the healthcare system, some participants insisted that: "It (technology) doesn't replace human contact". Others were ready to use the system as a communication tool with their patients, including videoconferencing and instant messaging (e.g. via Skype ${ }^{\circledR}$ ) to provide feedback to patients. This was one of the factors they suggested might enhance patients' readiness to use the system.

In terms of content and organization, most of all the health professionals wanted the Internet-based program to be simple and easy to use and be self-explanatory by providing information on the pain management program, the roles of the different health care team members, and the tools for patients. In this way, the Internet-based program could be used by patients before their initial visit to the pain clinic. Other features that emerged during the interaction between participants were a forum section, a frequently asked questions section for patients and caregivers, and video testimonials from peers. Also, the participants in one of the two focus group sessions suggested having 'stratified access' to the Internet-based program. The tool would be organized by level of information according to the care phase, and patients would be given the login details by the healthcare providers: for example, at the primary care level (general practitioner/family physician visit), they would have access to the basic section of the Internet-based program; at the specialty pain clinic, they would have access to a more detailed section with lessons and tools provided by the health professional concerned. The second focus group proposed two separate sections: a general public section and an optional personalizable section.

\subsubsection{Individuals with chronic pain and caregivers}

Themes from the patients' perspective included the importance of personal characteristics, end-of-program crash, role of medication, essential features for Internet-based programs, and non-medical information including motivational content.

Personal characteristics was an important theme emerging from the two patient focus group sessions. Patients and caregivers mentioned anger, denial (difficulty accepting), stress, depression, and feeling useless.

Regarding their views on chronic pain treatment and management, there were some similarities with health professionals, such as the end-of-program crash: "People who leave here [the chronic pain program], they're lost. It's like a baby tiger or lion in a zoo, when you release [it] into the wild". The patients who attended group sessions would prefer subgroups by type of pain condition and more focus on individual needs (more homogeneous groups: by type of pain or pain location, or more specialization of care). While most of them acknowledged the role of medication, they mentioned the problem of polymedication, often with different prescriptions form different doctors, and concluded that medication was a "nec- essary evil". Some participants mentioned their frustration and disappointment with the healthcare system, including the feeling of being "subjects in an experiment". Some participants would like to see more attention given to complementary and alternative medicine (e.g. acupuncture, massage, homeopathy) while others pointed out the related problem of belief (even with conventional medicine) and cost: "whether it's acupuncture or homeopathy, it's all the same. You have to believe."

Self-management was defined in different ways: find out how to control the pain oneself, know how to manage or learn to live with ups-and-downs, apply health information found on the Internet, get used to new body limitations because of the pain.

Another theme related to the treatment and management of pain was the problem of employment and income. Some patients mentioned difficulty getting hired and/or absence of a recognized diagnosis to qualify for disability benefits.

Essential features of an Internet-based program: patients thought the tool should be simple, user-friendly with a little animation, bilingual, use language that patients can understand with clickable definitions when necessary, and be accessible via mobile devices. The program could have a basic section on chronic pain and common problems such as depression, and different sections by type of pain condition. The participants also mentioned the addition of a chat section moderated by health professionals (to make it trustworthy), and a section for caregivers.

Regarding the content, the participants also suggested nonmedical activities of daily living. Information on lifestyle and social support included practical tips (such as instructions or testimonials on effective use of the keyboard to minimize pain), stress management, diet for chronic pain patients, tutorials or questionand-answer sections, legal procedures with respect to disability status and benefits since "the battles that you have to deal with are sometimes worse than your chronic pain"; "That's right; it's more stressful than the whole thing"; "Websites that can help you get through these painful processes, and it's not the physical pain, it's the mental pain." Some participants described the Internet-based program as a support against loneliness and repository to access the documents provided during pain management group sessions "because even if you think you have all the answers, you don't. And by having somebody or some link you can go to, it gives an extra boost to your morale." "I love it because it would really keep me motivated and on the straight and narrow. I'd be able to feel part of something instead of nothing, because right now, I'm in the middle of nothing."

The participants also wanted pragmatic and motivational content such as daily thoughts or tips on the homepage and a suggestion box: "As much [information] as possible you can get on the website. The more information, the more knowledge, the better off you are."

While the majority of participants thought they would like a system that provided a rating tool and showed progress: "That'd be great. I'd like it, you know why? Because sometimes I forget what I have", at least one participant was not interested for she did not want to see "small bars going up and down" that would affect her morale.

\subsection{Summary of results from the literature and focus groups}

Using the data gathered from the literature review and focus group sessions, we summarized the features needed for an Internet-based chronic pain self-management program (Table 4). Features that emerged from the focus groups but were not identified in the literature included condition-specific information in generic Internet-based programs, a "My care team" page that could show a diagram of the different health professionals involved in the patient's care with a brief explanation of how they interact, non-medical information (lifestyle and social support) such 
Table 4

Characteristics and features needed for an Internet-based chronic pain selfmanagement program.

\begin{tabular}{|c|c|c|}
\hline $\begin{array}{l}\text { Content and design } \\
\text { features }\end{array}$ & Examples & Gaps $^{a}$ \\
\hline $\begin{array}{l}\text { Automatic functions } \\
\text { Enriched } \\
\text { information } \\
\text { environment }\end{array}$ & $\begin{array}{l}\text { - Importance of the } \\
\text { quantity of information } \\
\text { provided: not too much } \\
\text { information } \\
\text { - Information provided in } \\
\text { a language patients can } \\
\text { understand with } \\
\text { clickable definitions } \\
\text { when necessary } \\
\text { - Repository of reliable } \\
\text { information, stratified } \\
\text { access according to } \\
\text { phase of care, i.e. health } \\
\text { professionals will } \\
\text { provide patients with } \\
\text { access to the appropriate } \\
\text { section of the system } \\
\text { - Non-medical } \\
\text { information (lifestyle } \\
\text { and social support) such } \\
\text { as practical tips, stress } \\
\text { management, legal } \\
\text { procedures with respect } \\
\text { to disability status and } \\
\text { benefits, community } \\
\text { services } \\
\text { - Section for family } \\
\text { members and caregivers, } \\
\text { asked questions section } \\
\text { - Tutorials or } \\
\text { question-and-answer } \\
\text { section, suggestion box } \\
\text { - } \\
\text { roles } \\
\text { informoning coping skills, } \\
\text { different health } \\
\text { - 'My care team' page with } \\
\text { a diagram of the } \\
\text { - }\end{array}$ & $\begin{array}{l}\text { Lack of } \\
\text { knowledge } \\
\text { Lack of } \\
\text { community } \\
\text { services } \\
\text { Self- } \\
\text { management } \\
\text { support }\end{array}$ \\
\hline $\begin{array}{l}\text { Automated tailored } \\
\text { feedback based on } \\
\text { individual progress } \\
\text { monitoring }\end{array}$ & $\begin{array}{l}\text { - Dynamic decision } \\
\text { support system for } \\
\text { tailored information and } \\
\text { feedback }\end{array}$ & \\
\hline $\begin{array}{l}\text { Automated } \\
\text { follow-up } \\
\text { messages }\end{array}$ & $\begin{array}{l}\text { - Motivational content like } \\
\text { pop-up statements, reward } \\
\text { system for activity } \\
\text { participation, tips from } \\
\text { peers, daily positive } \\
\text { thoughts }\end{array}$ & \\
\hline $\begin{array}{l}\text { Communicative funct } \\
\text { Access to advisor } \\
\text { for advice }\end{array}$ & $\begin{array}{l}\text { - Integrated email } \\
\text { application }\end{array}$ & $\begin{array}{l}\text { Patient- } \\
\text { provider } \\
\text { communication }\end{array}$ \\
\hline $\begin{array}{l}\text { Scheduled contact } \\
\text { with advisor }\end{array}$ & $\begin{array}{l}\text { - Chat-room application } \\
\text { for interaction with } \\
\text { health professionals }\end{array}$ & $\begin{array}{l}\text { Limited access } \\
\text { to healthcare }\end{array}$ \\
\hline
\end{tabular}

Table 4 (Continued)

\begin{tabular}{|c|c|c|}
\hline $\begin{array}{l}\text { Content and design } \\
\text { features }\end{array}$ & Examples & Gaps $^{\mathrm{a}}$ \\
\hline Peer-to-peer access & $\begin{array}{l}\text { - Forum/chat-room } \\
\text { applications for } \\
\text { interaction with both } \\
\text { other users and health } \\
\text { professionals }\end{array}$ & \\
\hline \multicolumn{3}{|c|}{ Use of supplementary modes } \\
\hline $\begin{array}{l}\text { Ubiquitous } \\
\text { accessibility }\end{array}$ & $\begin{array}{l}\text { - Accessible via computer } \\
\text { and mobile devices, } \\
\text { relevant applications for } \\
\text { mobile devices }\end{array}$ & \\
\hline Multimediality & $\begin{array}{l}\text { - Provide material in } \\
\text { written, audio, video } \\
\text { formats }\end{array}$ & \\
\hline $\begin{array}{l}\text { Password- } \\
\text { protected and } \\
\text { secure area for } \\
\text { personal health } \\
\text { records }\end{array}$ & $\begin{array}{l}\text { - Provide access to } \\
\text { medication list }\end{array}$ & $\begin{array}{l}\text { Coordination of } \\
\text { care }\end{array}$ \\
\hline
\end{tabular}

a Categories of gaps identified from the articles and the focus group sessions.

as practical tips, legal procedures with respect to disability status and benefits, directory of community services that patients could rate and update, tutorials or question-and-answer section, suggestion box, frequently asked questions section for caregivers, and Internet-based programs accessible via mobile devices with relevant applications.

\section{Discussion}

The strength of this study stems from the combination of focus group data from both patients and healthcare providers with findings from the literature based on existing Internet-based programs for chronic pain management. This approach allowed us to make recommendations not only concerning content (as was the case in previous studies) but also the optimal features when developing an Internet-based program, as well as future directions in the research, development and implementation of Internet-based programs for chronic pain care and management.

Internet-based chronic pain programs appear to be an acceptable way for health professionals to provide chronic pain care and self-management support, and studies have shown that adolescents [59,61] as well as older adults [62] will use and can benefit from online interventions. Several studies and reviews have demonstrated the feasibility of Internet-based chronic pain management programs as a complement to the usual care, and studies have shown promising outcomes, such as modest improvements, including better knowledge about chronic pain and how to manage it, pain reduction, and enhanced functional status $[19,22,41,42,57,62-65]$. The challenge is to develop Internet-based programs that will be sustainable over the long-term and can be integrated into the chronic pain care management process.

Our results showed that Internet-based programs may also help address the following gaps in the management of chronic pain: lack of continuity of care, lack of self-management support, and difficulty accessing psychological services, allied health professionals (qualified therapists) and pain management specialists. The aim of this study was to identify features for an Internet-based program that would be beneficial in terms of improving chronic pain management by the care team and providing patient self-management support.

While the objectives of the studies included in the literature review ranged from describing the usability of Internet-based 
programs to examining the feasibility and effectiveness of Internetbased interventions, there was a general lack of information on the association between the Internet-based programs' features and outcomes. Features that seem to positively affect outcomes include the integration of interactive features with personalization capabilities and some monitoring by health professionals [57,61,66-68]. According to Riva et al., interactive features of Internet-based programs contributed to improving patient empowerment 'while purely static elements with information only did not' [54]. With the drop-out problem inherent to Internet-delivered health care interventions, interactivity is one feature that can encourage longterm engagement $[58,59,66,69]$. Even minimal therapist contact and tailored messages have been found to correlate with lower drop-out rates [70-72]. For example, periodic telephone or email contacts was one way to improve motivation and adherence, and the communication method can be tailored to individual preferences $[73,74]$. However, the current state of the literature does not define the degree of interactivity or appropriate amount of human support. It is also worth noting that no study mentioned the use of quality appraisal tools to evaluate the quality of Internet-based programs $[44,45,75-77]$. Using tools such as the DISCERN questionnaire, a generic critical appraisal tool [77], or chronic pain-specific tools such as the Quality Website Index (QWI) [45] and the quality score, including chronic pain technical and chronic pain quality components [76], will help to compare results across studies and generate much-needed evidence concerning the effectiveness of Internet-based chronic pain management programs.

The focus group approach used in this study is a good way to explore people's knowledge and experiences and observe interactions related to a set of attitudes and experiences [78]. Conducting separate sessions for health professionals and individuals with chronic pain was important for optimal interactions because the information elicited is very much a function of group interaction [79]. The focus group results showed some commonalities between the views and needs of health professionals and their clients with chronic pain. Regarding the treatment and management of chronic pain, both groups mentioned the end-of-program crash and recognized the potential role of an Internet-based program to help with the transition and post-program follow-up. An end-of-program crash might be indicative of a high degree of satisfaction with the multidisciplinary chronic pain management program offered to participants and its short duration, an association worth exploring in future studies. The role of Internet-based programs in the healthcare system was seen as complementary and not designed to replace face-to-face contact or alienate health professionals. One health professional considered the possibility of using an Internet-based program during consultations, as suggested by Caiata Zufferey and Schulz [66], i.e., using the program as a complement to the medical consultation in order to increase its immediate credibility and direct patients to use it. This may encourage patients to share information found on the Internet as recent surveys found that only a minority of patients share pain-related health care information found on the Internet with their healthcare providers $[80,81]$. Another theme common to both groups was the financial issue related to employment and disability benefits, which affects the ability of individuals with chronic pain to pay for allied health professional services that are needed when public clinic-based chronic pain management programs end.

Regarding the structure of the content of Internet-based programs, individuals with chronic pain suggested a common basic section and different sections specific to various types of chronic pain. Health professionals suggested stratified access to information based on the patient's stage of advancement; a similar recommendation was made by the authors of the 'Oneself' tool $[58,66]$. While health professionals mainly considered Internetbased programs to be a technology for educating their clients, individuals with chronic pain considered it to be a repository of trustworthy documents to help them self-manage their pain, as well as useful tips for daily living activities, including information on diet and legal procedures with third-party payers. Trust was mentioned as a determinant of the usage pattern of Internet-based programs in previous studies [70,82]. Of the common features identified from the literature review (Table 1 ), only the dynamic decision support system was not mentioned by the focus group participants. Conversely, only one Internet-based program has integrated personal health records while the patient participants in our study and other studies emphasized the need for and value of these records [83-85].

Finally, the diversity of the platforms (computer, smartphone, tablet) is important because not all people with chronic pain can afford a computer. The next generation of Internet-based chronic pain management programs should integrate applications (apps) not only for obvious reasons of accessibility and flexibility but also for security and trustworthiness, as $86 \%$ of apps for pain conditions reported no involvement by healthcare professionals [86]. Future studies will also have to examine strategies to improve engagement and investigate the association between specific mechanisms whereby features are expected to have an impact on outcomes, including the care process, changes in individual health behaviours, and improved patient function. The suggested characteristics needed for an Internet-based chronic pain management programs (Table 4), including the security aspects of such a tool outlined by Wakefield et al. [87], will evolve as more information and evidence become available.

\subsection{Limitations}

Only Internet-based programs that were the subject of scientific publications and were designed to support patient selfmanagement and enhance patient-provider communications were selected. The aim of the study was not to explore the effectiveness of these online programs in terms of outcomes, but to identify the features and modes of delivery; therefore, no quality assessment was performed. Other limitations included the small size of the convenience sample, the absence of representatives from some health professions in the focus groups such as occupational therapists, and the fact that patient and caregiver participants did not have handson experience with an Internet-based self-management program. This may explain why $44 \%$ of them did not support using the Internet for health information, which points to the need to explore ways to promote patient access to and interest in using online interventions. Nevertheless, since findings from the focus groups were mostly supported by studies that conducted similar individual and focus group interviews [88-90], we are confident that we were able to identify the most relevant features to inform the development of and evaluate an Internet-based chronic pain self-management program in future research.

\section{Conclusion}

Internet-based programs contain automated, communication and decision support features that can address information and care gaps reported by patients and clinicians. However, non-medical information, condition- and context-specific information, integration of personal health records, and the role of the different health professionals in chronic pain management were not identified in existing systems reported in the literature but need to be considered in the future development of Internet-based programs. While the association between the features of Internet-based programs and patient long-term engagement and outcomes is not clearly established, the results of this study indicate that interactivity, per- 


\section{Summary points}

What was already known on the topic

- Self-management has the potential to optimize health outcomes in the management of chronic pain

- Self-management support is rarely integrated into regular care team activities and the medical treatment patients receive

- Adolescents as well as adults can benefit from online interventions

What this study added to our knowledge

- Minimum features needed for an Internet-based selfmanagement program include interactivity, personalization and automated tailored messages

- Inclusion of non-medical information such as lifestyle and tips from peers is as important as medical information

- Need to empirically determine the association between different features of Internet-based programs and health outcomes

sonalization and tailored messages as well as therapist contact are likely to maximize the effectiveness of an Internet-based chronic pain program in enhancing self-management.

\section{Conflict of interest}

None declared.

\section{Author contributions}

AG conceived the study, collected the data, performed the analysis and drafted the manuscript.

RV, CA, and LB-L contributed to the study design and revised the manuscript. IS contributed to the data collection and analysis. $\mathrm{LP}, \mathrm{MW}, \mathrm{YS}$, and NV revised the manuscript. SA conceived the study, contributed to the interpretation of the data and revised the manuscript. All authors revised the draft and approved the final version of the manuscript.

\section{Acknowledgments}

This study was supported by a grant from the Richard and Edith Strauss Canada Foundation. The authors thank Jill Boruff for optimizing the search strategy, Suzan Cohen for her assistance with conducting the focus groups and transcribing the audiotapes, and the clinical and managerial staff of the chronic pain program at three clinical sites (Constance Lethbridge Rehabilitation Centre, Institut de Réadaptation Gingras-Lindsay de Montréal, and MUHC Alan Edwards Pain Management Unit) for their assistance with recruiting participants. Last but not least, the authors thank the study participants. Amédé Gogovor is funded by an FRQS doctoral award and Sara Ahmed is funded by an FRQS research career award.

\section{Appendix A. Supplementary data}

Supplementary data associated with this article can be found, in the online version, at http://dx.doi.org/10.1016/j.ijmedinf.2016. 10.005 .

\section{References}

[1] World Health Organization supports global effort to relieve chronic pain, 2004.

[2] Costs of Chronic Pain, European Pain Federation (EFIC), 2012.

[3] H. Breivik, B. Collett, V. Ventafridda, R. Cohen, D. Gallacher, Survey of chronic pain in Europe: prevalence, impact on daily life, and treatment, Eur. J. Pain 10 (2006) 287-333.
[4] J. Hardt, C. Jacobsen, J. Goldberg, R. Nickel, D. Buchwald, Prevalence of chronic pain in a representative sample in the United States, Pain Med. 9 (2008) 803-812.

[5] A. Tsang, K.M. Von, S. Lee, J. Alonso, E. Karam, M.C. Angermeyer, G.L. Borges, E.J. Bromet, K. Demytteneare, G.G. de, G.R. de, O. Gureje, J.P. Lepine, J.M. Haro, D. Levinson, M.A. Oakley Browne, J. Posada-Villa, S. Seedat, M. Watanabe, Common chronic pain conditions in developed and developing countries: gender and age differences and comorbidity with depression-anxiety disorders, J. Pain 9 (2008) 883-891.

[6] D.C. Turk, Clinical effectiveness and cost-effectiveness of treatments for patients with chronic pain, Clin. J. Pain 18 (2002) 355-365.

[7] M.L. Reitsma, J.E. Tranmer, D.M. Buchanan, E.G. Vandenkerkhof, The prevalence of chronic pain and pain-related interference in the Canadian population from 1994 to 2008, Chronic Dis. Inj. Can. 31 (2011) 157-164.

[8] N.K. Tang, C. Crane, Suicidality in chronic pain: a review of the prevalence, risk factors and psychological links, Psychol. Med. 36 (2006) 575-586.

[9] S.H. Sanders, R.N. Harden, P.J. Vicente, Evidence-Based clinical practice guidelines for interdisciplinary rehabilitation of chronic nonmalignant pain syndrome patients, Pain Pract. 5 (2005) 303-315.

[10] National Pain Strategy Pain Management for All Australians, 2010.

[11] Agence d'évaluation des technologies et des modes d'intervention en santé (AETMIS), Management of Chronic (Non-Cancer) Pain: Organization of Health Services (AETMIS 06-04), Montréal: AETMIS, 2006, xv-85 pp.

[12] P.L. Dobkin, L.J. Boothroyd, Organizing health services for patients with chronic pain: when there is a will there is a way, Pain Med. 9 (2008) 881-889.

[13] C. Phillips, C. Main, R. Buck, M. Aylward, G. Wynne-Jones, A. Farr, Prioritising pain in policy making: the need for a whole systems perspective, Health Policy 88 (2008) 166-175

[14] Institute of Medicine, Priority Areas for National Action: Transforming Health Care Quality, The National Academies Press, Washington, DC, 2003.

[15] M.M. Funnell, H.R. Anderson, Putting Humpty Dumpty back together again: reintegrating the clinical and behavioral components in diabetes care and education, Diab. Spectr. 12 (1999) 19-23.

[16] R.E. Glasgow, C.L. Davis, M.M. Funnell, A. Beck, Implementing practical interventions to support chronic illness self-management, Jt. Comm. J. Qual. Saf. 29 (2003) 563-574.

[17] S.E. Ross, L.A. Moore, M.A. Earnest, L. Wittevrongel, C.T. Lin, Providing a web-based online medical record with electronic communication capabilities to patients with congestive heart failure: randomized trial, J. Med. Internet Res. 6 (2004).

[18] D. Wiljer, K.J. Leonard, S. Urowitz, E. Apatu, C. Massey, N.K. Quartey, P. Catton, The anxious wait: assessing the impact of patient accessible EHRs for breast cancer patients, BMC Med. Inform. Decis. Mak. 10 (2010) 46.

[19] J.L. Bender, A. Radhakrishnan, C. Diorio, M. Englesakis, A.R. Jadad, Can pain be managed through the Internet? A systematic review of randomized controlled trials, Pain 152 (2011) 1740-1750.

[20] C. Eccleston, T.M. Palermo, A.C. Williams, A. Lewandowski Holley, S. Morley, E. Fisher, E. Law, Psychological therapies for the management of chronic and recurrent pain in children and adolescents, Cochrane Database Syst. Rev. 5 (2014) Cd003968.

[21] A.A. Heapy, D.M. Higgins, D. Cervone, L. Wandner, B.T. Fenton, R.D. Kerns, A systematic review of technology-assisted self-management interventions for chronic pain: looking across treatment modalities, Clin. J. Pain 31 (2015) 470-492.

[22] D.D. Macea, K. Gajos, Y.A. Daglia Calil, F. Fregni, The efficacy of web-based cognitive behavioral interventions for chronic pain: a systematic review and meta-analysis, J. Pain 11 (2010) 917-929.

[23] D.W. Bates, M. Ebell, E. Gotlieb, J. Zapp, H.C. Mullins, A proposal for electronic medical records in U.S. primary care, J. Am. Med. Inform. Assoc. 10 (2003) $1-10$

[24] Z.T. Bloomgarden, International Diabetes Federation meeting, 1997. Neuropathy, information technology, cost of diabetes care, and epidemiology, Diab. Care 21 (1998) 1198-1202.

[25] D.F. Lobach, R. Low, J.A. Arbanas, J.S. Rabold, J.L. Tatum, S.D. Epstein, Defining and supporting the diverse information needs of community-based care using the web and hand-held devices, Proc. AMIA. Annu. Fall Symp. (2001) 398-402.

[26] C.J. McDonald, The Promise of Computerized feedback systems for diabetes care, Am. Coll. Phys. 124 (1996) 170-174.

[27] B. Morlion, Y. Verbandt, M. Paiva, M. Estenne, A. Michils, P. Sandron, C. Bawin, P. Assis-Arantes, A telemanagement system for home follow-up of respiratory patients, IEEE Eng. Med. Biol. Mag. 18 (1999) 71-79.

[28] R. Noffsinger, S. Chin, Improving the delivery of care and reducing healthcare costs with the digitation of information, J. Healthc. Inf. Manag. 14 (2000) 23-30.

[29] L. Norman, P. Hardin, E. Lester, S. Stinton, E.C. Vincent, Computer-assisted quality improvement in an ambulatory care setting: a follow-up report, J. Qual. Improv. 21 (1995) 116-131.

[30] E. Ortiz, E. Meyer, H. Burstin, The role of clinical informatics in the agency for healthcare research and quality's efforts to improve patient safety, Proc./AMIA Ann. Symp. (2001) 508-512.

[31] A.M. Patel, Using the Internet in the management of asthma, Curr. Opin. Pulm. Med. 7 (2001) 39-42 [Review] [24 refs].

[32] S. Shea, J. Starren, R.S. Weinstock, P.E. Knudson, J. Teresi, D. Holmes, W. Palmas, L. Field, R. Goland, C. Tuck, G. Hripcsak, L. Capps, D. Liss, Columbia 
university's informatics for diabetes education and telemedicine (IDEATel) project: rationale and design, J. Am. Med. Inform. Assoc. 9 (2002) 49-62 [see comments].

[33] P. Sonksen, C. Williams, Information technology in diabetes care 'Diabeta': 23 years of development and use of a computer-based record for diabetes care, Int. J. Biomed. Comput. 42 (1996) 67-77.

[34] W.W. Stead, R.A. Miller, M.A. Musen, W.R. Hersh, Integration and beyond: linking information from disparate sources andinto workflow, J. Am. Med. Inform. Assoc. 7 (2000) 135-145.

[35] E.E. Westberg, R.A. Miller, The basis for using the internet to support the information needs of primary care, J. Am. Med. Inform. Assoc. 6 (1999) 6-25.

[36] N. Wilson, O. Mansoor, D. Simmons, Diabetes in new Zealand-better information needed, N. Z. Med. J. 112 (1999) 206-208.

[37] M. Eccles, E. McColl, N. Steen, N. Rousseau, J. Grimshaw, D. Parkin, I. Purves, Effect of computerised evidence based guidelines on management of asthma and angina in primary care: cluster randomised controlled trial, $\mathrm{Br}$. Med. J. 325 (2002) 941-947.

[38] R.N. Shiffman, Y. Liaw, D.D. Navedo, K.A. Freudigman, User satisfaction and frustration with a handheld, pen-based guideline implementation system for asthma, Proc./AMIA Annu. Symp. (1999) 940-944.

[39] C. Sicotte, J.L. Denis, P. Lehoux, F. Champagne, The computer-based patient record challenges towards timeless and spaceless medical practice, J. Med. Syst. 22 (1998) 237-256.

[40] R. Roine, A. Ohinmaa, D. Hailey, Assessing telemedicine: a systematic review of the literature, CMAJ 165 (2001) 765-771.

[41] G. Andersson, B. Ljotsson, C. Weise, Internet-delivered treatment to promote health, Curr. Opin. Psychiatry 24 (2011) 168-172.

[42] P. Cuijpers, A. van Straten, G. Andersson, Internet-administered cognitive behavior therapy for health problems: a systematic review, J. Behav. Med. 31 (2008) 169-177.

[43] C. Eccleston, E. Fisher, L. Craig, G.B. Duggan, B.A. Rosser, E. Keogh, Psychological therapies (Internet-delivered) for the management of chronic pain in adults, Cochrane Database Syst. Rev. 2 (2014) Cd010152.

[44] L. Butler, N.E. Foster, Back pain online: a cross-sectional survey of the quality of web-based information on low back pain, Spine 28 (2003) 395-401.

[45] T.A. Washington, G.J. Fanciullo, J.A. Sorensen, J.C. Baird, Quality of chronic pain websites, Pain Med. 9 (2008) 994-1000.

[46] R.A. Krueger, M.A. Casey, Focus Groups: a Practical Guide for Applied Research, Sage Publications, Thousand Oaks Calif, 2000.

[47] J. Sim, Collecting and analysing qualitative data: issues raised by the focus group, J. Adv. Nurs. 28 (1998) 345-352.

[48] T.M. Chiu, G. Eysenbach, Theorizing the health service usage behavior of family caregivers: a qualitative study of an internet-based intervention, Int. J. Med. Inform. 80 (2011) 754-764.

[49] S. Ahmed, S.J. Bartlett, P. Ernst, G. Pare, M. Kanter, R. Perreault, R. Grad, L. Taylor, R. Tamblyn, Effect of a web-based chronic disease management system on asthma control and health-related quality of life: study protocol for a randomized controlled trial, Trials 12 (2011) 260.

[50] L.T. Webb, J. Joseph, L. Yardley, S. Michie, Using the internet to promote health behavior change: a systematic review and meta-analysis of the impact of theoretical basis, use of behavior change techniques, and mode of delivery on efficacy, J. Med. Internet Res. 12 (2010) e4.

[51] V. Braun, V. Clarke, Using thematic analysis in psychology, Qual. Res. Psychol. 3 (2006) 77-101.

[52] E. Keogh, B.A. Rosser, C. Eccleston, e-Health and chronic pain management: current status and developments, Pain 151 (2010) 18-21.

[53] R.C. Polomano, N. Droog, M.C. Purinton, A.S. Cohen, Social support web-based resources for patients with chronic pain, J. Pain Palliat. Care Pharmacother. 21 (2007) 49-55

[54] S. Riva, A.L. Camerini, A. Allam, P.J. Schulz, Interactive sections of an Internet-based intervention increase empowerment of chronic back pain patients: randomized controlled trial, J. Med. Internet Res. 16 (2014) e180.

[55] D.A. Williams, Web-based behavioral interventions for the management of chronic pain, Curr. Rheumatol. Rep. 13 (2011) 543-549.

[56] D.A. Williams, D. Kuper, M. Segar, N. Mohan, M. Sheth, D.J. Clauw, Internet-enhanced management of fibromyalgia: a randomized controlled trial, Pain 151 (2010) 694-702.

[57] P.J. Schulz, S. Rubinelli, M.C. Zufferey, U. Hartung, Coping with chronic lower back pain: designing and testing the online tool ONESELF, J. Comput. Mediated Commun. 15 (2010) 625-645.

[58] P.J. Schulz, S. Rubinell, U. Hartung, An internet-based approach to enhance self-managementof chronic low back pain in the italian-speaking population of Switzerland: results from a pilot study, Int. J. Public Health 52 (2007) 286-294.

[59] J. Stinson, P. McGrath, E. Hodnett, B. Feldman, C. Duffy, A. Huber, L. Tucker, R. Hetherington, S. Tse, L. Spiegel, S. Campillo, N. Gill, M. White, Usability testing of an online self-management program for adolescents with juvenile idiopathic arthritis, J. Med. Internet Res. 12 (2010) e30.

[60] E. Trautmann, B. Kröner-Herwig, Internet-Based self-Help training for children and adolescents with recurrent headache: a pilot study, Behav. Cogn. Psychother. 36 (2008) 241-245.

[61] A.C. Long, T.M. Palermo, Brief report: web-based management of adolescent chronic pain: development and usability testing of an online family cognitive behavioral therapy program, J. Pediatr. Psychol. 34 (2009) 511-516.
[62] R.L. Berman, M.A. Iris, R. Bode, C. Drengenberg, The effectiveness of an online mind-body intervention for older adults with chronic pain, J. Pain 10 (2009) 68-79.

[63] G. Brattberg, Internet-based rehabilitation for individuals with chronic pain and burnout II: a long-term follow-up, Int. J. Rehabil. Res. 30 (2007) $231-234$.

[64] T.M. Palermo, A.C. Wilson, M. Peters, A. Lewandowski, H. Somhegyi, Randomized controlled trial of an Internet-delivered family cognitive-behavioral therapy intervention for children and adolescents with chronic pain, Pain 146 (2009) 205-213.

[65] L.S. Ruehlman, P. Karoly, C. Enders, A randomized controlled evaluation of an online chronic pain self management program, Pain 153 (2011) 319-330.

[66] M. Caiata Zufferey, P.J. Schulz, Self-management of chronic low back pain: an exploration of the impact of a patient-centered website, Patient Educ. Couns. 77 (2009) 27-32.

[67] S. Garg, D. Garg, T.C. Turin, M.F.U. Chowdhury, Web-based interventions for chronic back pain: a systematic review, J. Med. Internet Res. 18 (2016) e139.

[68] O.B. Kristjansdottir, E.A. Fors, E. Eide, A. Finset, D.S. van, S.H. Wigers, H. Eide, Written online situational feedback via mobile phone to support self-management of chronic widespread pain: a usability study of a web-based intervention, BMC Musculoskelet. Disord. 12 (2011) 51.

[69] K.L. Funk, V.J. Stevens, L.J. Appel, A. Bauck, P.J. Brantley, C.M. Champagne, J. Coughlin, A.T. Dalcin, J. Harvey-Berino, J.F. Hollis, G.J. Jerome, B.M. Kennedy, L.F. Lien, V.H. Myers, C. Samuel-Hodge, L.P. Svetkey, W.M. Vollmer, Associations of internet website use with weight change in a long-term weight loss maintenance program, J. Med. Internet Res. 12 (2010) e29.

[70] N.R. Hardiker, M.J. Grant, Factors that influence public engagement with eHealth: a literature review, Int. J. Med. Inf. 80 (2011) 1-12.

[71] O.B. Kristjansdottir, E.A. Fors, E. Eide, A. Finset, T.L. Stensrud, S. van Dulmen, S.H. Wigers, H. Eide, A smartphone-based intervention with diaries and therapist-feedback to reduce catastrophizing and increase functioning in women with chronic widespread pain: randomized controlled trial, J. Med. Internet Res. 15 (2013) e5.

[72] B.A. Rosser, C. Eccleston, Promoting self-management through technology: SMART solutions for long-term health conditions, J. Integr. Care 17 (2009) 10-19.

[73] G. Andersson, P. Lundstrom, L. Strom, Internet-based treatment of headache: does telephone contact add anything? Headache 43 (2003) 353-361.

[74] M. Buhrman, E. Nilsson-Ihrfeldt, M. Jannert, L. Strom, G. Andersson, Guided internet-based cognitive behavioural treatment for chronic back pain reduces pain catastrophizing: a randomized controlled trial, J. Rehabil. Med. 43 (2011) 500-505.

[75] S.J. Bailey, D.L. LaChapelle, S.M. LeFort, A. Gordon, T. Hadjistavropoulos, Evaluation of chronic pain-related information available to consumers on the internet, Pain Med. 14 (2013) 855-864.

[76] T.B. Corcoran, A. Haigh, F. Fau- Seabrook, S.A. Seabrook, A. Fau- Schug, S.A. Schug, The quality of internet-sourced information for patients with chronic pain is poor, Clin. J. Pain 25 (2010) 617-623.

[77] J. Kaicker, V.B. Debono, W. Dang, N. Buckley, L. Thabane, Assessment of the quality and variability of health information on chronic pain websites using the DISCERN instrument, BMC Med. 8 (2010).

[78] J. Kitzinger, Qualitative research. Introducing focus groups, BMJ 311 (1995) 299-302.

[79] M.A. Carey, Comment: concerns in the analysis of focus group data, Qual. Health Res. 5 (1995) 487-495.

[80] T.B. Corcoran, A. Haigh, F. Fau- Seabrook, S.A. Seabrook, A. Fau- Schug, S.A. Schug, A survey of patients' use of the internet for chronic pain-related information, Pain Med. 11 (2010) 512-517.

[81] L.M. Shinchuk, V. Chiou, P. Fau- Czarnowski, A.L. Czarnowski, V. FauMeleger, A.L. Meleger, Demographics and attitudes of chronic-pain patients who seek online pain-related medical information: implications for healthcare providers, Am. J. Phys. Med. Rehabil. 89 (2010) 146.

[82] M. Lemire, G. Pare, C. Sicotte, C. Harvey, Determinants of Internet use as a preferred source of information on personal health, Int. J. Med. Inf. 77 (11) (2008) 723-734.

[83] D. Kaelber, E.C. Pan, The value of personal health record (PHR) systems, AMIA Annu. Symp. Proc. 6 (2008) 343-347.

[84] D.C. Kaelber, A.K. Jha, D. Johnston, B. Middleton, D.W. Bates, A research agenda for personal health records (PHRs), J. Am. Med. Inform. Assoc. 15 (2008) 729-736.

[85] S. Urowitz, D. Wiljer, E. Apatu, G. Eysenbach, C. Delenardo, T. Harth, H. Pai, K.J. Leonard, Is Canada ready for patient accessible electronic health records? A national scan, BMC Med. Inform. Decis. Mak. 8 (2008) 33.

[86] B.A. Rosser, C. Eccleston, Smartphone applications for pain management, J. Telemed. Telecare 17 (2011) 308-312.

[87] D.S. Wakefield, D. Mehr, L. Keplinger, S. Canfield, R. Gopidi, B.J. Wakefield, R.J. Koopman, J.L. Belden, R. Kruse, K.M. Kochendorfer, Issues and questions to consider in implementing secure electronic patient-provider web portal communications systems, Int. J. Med. Inform. 79 (2010) 469-477.

[88] S.K. Moore, H. Guarino, M.C. Acosta, I.D. Aronson, L.A. Marsch, A. Rosenblum, M.J. Grabinski, D.C. Turk, Patients as collaborators: using focus groups and feedback sessions to develop an interactive, web-based self-management intervention for chronic pain, Pain Med. 14 (2013) 1730-1740.

[89] M. Nielsen, G. Jull, P.W. Hodges, Information needs of people with low back pain for an online resource: a qualitative study of consumer views, Disabil. Rehabil. 36 (2014) 1085-1091. 
[90] J. Stinson, M. White, L. Isaac, F. Campbell, S. Brown, D. Ruskin, A. Gordon, M. Galonski, L. Pink, N. Buckley, J.L. Henry, C. Lalloo, A. Karim, Understanding the information and service needs of young adults with chronic pain: perspectives of young adults and their providers, Clin. J. Pain. 29 (2013) 600-612.

[91] K.M. Carpenter, S.A. Stoner, J.M. Mundt, B. Stoelb, An online self-help CBT intervention for chronic lower back pain, Clin. J. Pain 28 (2012) 14-22.

[92] E. Chiauzzi, L.A. Pujol, M. Wood, K. Bond, R. Black, E. Yiu, K. Zacharoff, PainACTION-back pain: a self-management website for people with chronic back pain, Pain Med. 11 (2010) 1044-1058

[93] T. Devineni, E.B. Blanchard, A randomized controlled trial of an internet-based treatment for chronic headache, Behav. Res. Ther. 43 (2005) $277-292$.

[94] C.L. Hicks, C.L. von Baeyer, P.J. McGrath, Online psychological treatment for pediatric recurrent pain: a randomized evaluation, J. Pediatr. Psychol. 31 (2006) 724-736

[95] A. Hochlehnert, A. Richter, H.B. Bludau, C. Bieber, K. Blumenstiel, K. Mueller, S. Wilke, W. Eich, A computer-based information-toot for chronic pain patients - computerized information to support the process of shared decision-making, Patient Educ. Couns. 61 (2006) 92-98.

[96] K.R. Lorig, P.L. Ritter, A. Dost, K. Plant, D.D. Laurent, I. McNeil, The expert patients programme online, a 1-year study of an Internet-based self-management programme for people with long-term conditions, Chronic Illn. 4 (2008) 247-256.
[97] K.R. Lorig P.L. Ritter, D.D. Laurent, K. Plant, The internet-based arthritis self-management program: a one-year randomized trial for patients with arthritis or fibromyalgia, Arthritis Rheum. 59 (2008) 1009-1017.

[98] C.N. Sciamanna, L.R. Harrold, M. Manocchia, N.J. Walker, S. Mui, The effect of web-based personalized, osteoarthritis quality improvement feedback on patient satisfaction with osteoarthritis care, Am. J. Med. Qual. 20 (2005) 127-137.

[99] M.J. Sorbi, S.B. Mak, H. Houtveen, A.M. Kleiboer, L.J.P. van Doornen, Mobile web-based monitoring and coaching: feasibility in chronic migraine, J. Med. Internet Res. 9 (2007).

[100] J.N. Stinson, P.J. McGrath, E.D. Hodnett, B.M. Feldman, C.M. Duffy, A.M. Huber, L.B. Tucker, C.R. Hetherington, S.M. Tse, L.R. Spiegel, S. Campillo, N.K. Gill, M.E. White, An internet-based self-management program with telephone support for adolescents with arthritis: a pilot randomized controlled trial, J. Rheumatol. 37 (2010) 1944-1952.

[101] M. Allen, L.I. Iezzoni, A. Huang, L. Huang, S.G. Leveille, Improving patient-clinician communication about chronic conditions: description of an internet-based nurse E-coach intervention, Nurs. Res. 57 (2008) 107-112.

[102] S.N. Weingart, D. Rind, Z. Tofias, D.Z. Sands, Who uses the patient internet portal? The PatientSite experience, J. Am. Med. Inform. Assoc. 13 (2006) 91-95.

[103] S.G. Leveille, A. Huang, S.B. Tsai, M. Allen, S.N. Weingart, L.I. Iezzoni, Health coaching via an internet portal for primary care patients with chronic conditions: a randomized controlled trial, Med. Care 47 (2009) 41-47. 